\title{
EVALUATION OF IMMUNE RESPONSES AGAINST THE PARASITE ICHTHYOPHTHIRIUS MULTIFILIIS BETWEEN CHANNEL CATFISH AND HYBRID CATFISH
}

\author{
De-Hai Xu and Phillip H. Klesius
}

\author{
U.S. Department of Agriculture, Agricultural Research Service, Aquatic Animal Health Research \\ Unit, 990 Wire Road, Auburn, AL 36832, USA
}

Channel catfish is a dominant aquaculture species in the USA and has been cultured for several decades. Recently, an increasing number of producers are showing an interest in the culture of hybrid catfish (channel catfish $\times$ blue catfish) instead of channel catfish due to its performance traits. The hybrid catfish has been reported to exhibit many commercially desirable characteristics, including faster growth, better feed conversion, low oxygen tolerance and resistance to some diseases. Ciliated protozoan

Ichthyophthirius multifiliis, commonly referred as Ich, is a serious parasite of freshwater fish and causes heavy economic loss in aquaculture. Chemical treatment of Ich infection is difficult after the parasite penetrates into the fish skin and gills. Vaccination against the parasite is an alternative to chemical treatments since fish that survive an Ich infection acquire immunity against reinfection by the parasite. There is limited information available on the immune protection of hybrid catfish against Ich. In this study, we evaluated immune responses and host protection between channel catfish and hybrid catfish using a cohabitation model. Channel catfish and hybrid catfish were put in the same tanks and subjected to the same treatment, including vaccination methods, parasite challenge concentration, infection duration, water quality, and feeding to evaluate fish immune protection against the parasite, whereby all environmental parameters would be consistent due to experimental animals being housed together in the same tank. Anti-Ich antibody levels were measured by immobilization assay and the immunized channel catfish and hybrid catfish showed a significantly higher anti-Ich antibody (titer > 3800) compared to nonimmunized controls (titer $<40$ ). After being challenged with live Ich theronts, the immunized channel catfish and hybrid catfish were not infected or only infected with a low number of the parasites $(<50$ trophonts per fish). The immunized fish showed a significantly higher survival rate (90-100\%) than nonimmunized controls $(0 \%)$. There is a positive correlation between anti-Ich antibody titers and fish survival. The immunized fish with the highest anti-Ich antibody titers showed the highest survival rate. There was no statistical difference $(p>0.05)$ on anti-Ich antibody titers, parasite infection level and fish survival rate between immunized channel catfish and hybrid catfish. Therefore, these results indicate that hybrid catfish do develop the same strong immune protection against Ich as its parent channel catfish. The results in this study will help fish farmers to select disease resistant fish to minimize the impact of disease on cultured fish.

\section{KEYWORDS}

Immune protection; vaccination; parasite; infection; survival

Tel.: +1 3348873741 ext. 120; Fax: +1 3348872983

E-mail address: dehai.xu@ars.usda.gov 